\title{
Can Big Data Save Labor Market Information Systems?
}

\author{
Eric M. Johnson
}

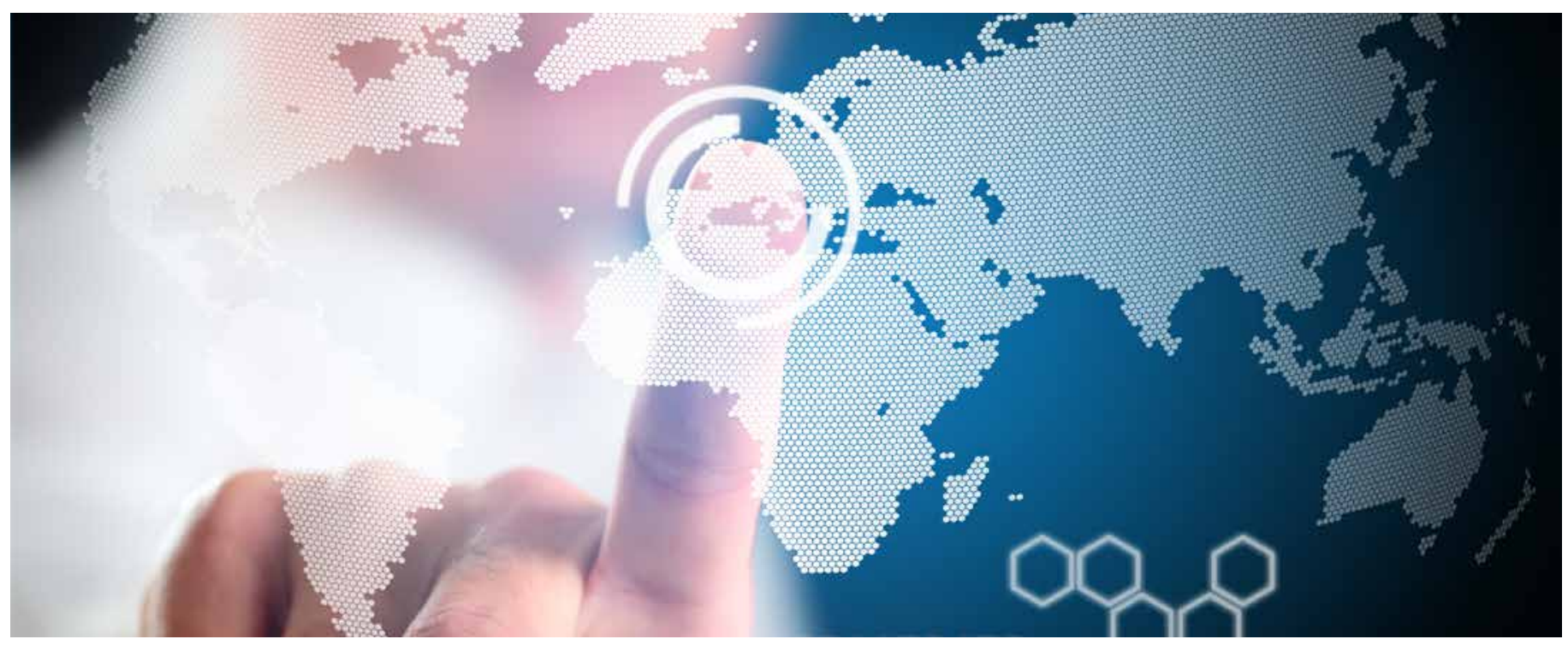

The US Department of Labor (DoL) announces its monthly "Employment Situation Report" at exactly 8:30 a.m. on the first Friday of every month. In a rare feat of bureaucratic theater, the announcement is covered live by throngs of reporters who are given advance reports and sworn to strict secrecy, the DoL going as far as cutting their Internet and phone connections. * Immediately on announcement, the jobs numbers course through the system, feeding financial analysts, media commentators, and policy researchers who eagerly await them. A bit more slowly, these data make their way

* See http://www.bloomberg.com/bw/articles/ 2012-04-18/on-jobs-day-tv-reporters-cant-move-amuscle for more detail on the restrictions imposed on reporters before the announcement.

\section{Key Policy Implications}

- Traditional approaches to providing labor market information (LMI) suffer from a number of challenges. These challenges are addressable but will need the attention of governments and their donor partners to resolve them.

- Real-time LMI has made advances with the rise of computational science techniques and the "big data" revolution. Use of these data approaches by high-profile actors in the United States (Federal Reserve Bank), Canada (Ministry of Finance), and Government of Singapore has provoked some to question how large of a role these data can and should have and to what extent big data are applicable to less-developed LMI systems.

- Given significant limitations to real-time LMI itself, including examples where real-time LMI leads to suspect policy action, some experts see it as a useful supplement—or an additional labor market "lubricant"—-but not as a replacement for or savior of traditional systems.

- Real-time LMI for special purposes and supplementary analysis is promising. Bringing these capabilities to developing world economies should be a priority for donors working in these areas. 
out through the broader US labor market information (LMI) system to career counselors, educators, and civil society groups, each of them reliant on timely labor market data. The two surveys that make up the report-a household survey of individuals and an establishment survey of employers-move markets, both financial and educational.

The spectacle of the monthly "jobs report," as it is more commonly known, illustrates the importance of LMI to the economy. Yet, one wonders how long the government-led monopoly on such data will last. Might government control of this area seem quaint when the data revolution (big data, open data, personalized data) fully arrives to the labor market? Will the services of groups like Burning Glass-a firm that analyzes millions of online job postings from thousands of websites every day-allow us to understand the labor market well before governments release their survey data? The US Federal Reserve Bank already uses such job posting analytics in its decision making, and the aforementioned DoL jobs report is itself upstaged by the Automatic Data Processing (ADP) Jobs Report, a scan of 400,000 private employers by payroll processing giant ADP. Last year, the Government of Singapore hired Burning Glass to help improve its labor market information system (LMIS), and Canada has turned to online classifieds provider, Kijiji, to help with theirs. What implications do these trends have for "traditional" LMIS-and for those countries trying to build new systems?

This policy brief explores this question, with a particular focus on developing world systems. Interviews conducted with officials from the World Bank, ILO, Inter-American Development Bank (IDB), the Asian Development Bank (ADB), and the United States Agency for International Development (USAID) - all supporters of LMIS improvements in developing countries-elucidate opportunities and challenges in changing LMI approaches.

\section{The Importance of LMI}

Like any market, labor markets need information to function effectively and efficiently. The International Labour Organization (ILO) defines LMI as "any information concerning the size and composition of the labour market or any part of the labour market, the way it or any part of it functions, its problems, the opportunities which may be available to it, and the employment-related intentions or aspirations of those who are part of it."1 "Real-time LMI," a term used throughout this brief, is LMI that is or can be provided in a matter of hours or days, mostly through webbased data analytics. ${ }^{2}$

Policy makers need data on labor supply and demand to chart economic and social policies. Educators need to know how industries are changing, particularly to gauge fluctuations in demand for certain knowledge, skills, and abilities. Career counselors need information on occupational profiles, educational requirements, work conditions, growth trajectories, and current openings to provide useful advice to job seekers. Media consumers demand information on the "hot jobs" and "top schools." Economy-wide, the ILO claims that LMI is critical to job creation, poverty reduction, social protection, adjusting to business cycle shocks, and maintaining competitiveness in an era of globalization. ${ }^{3}$

For these reasons, the United States spends nearly $\$ 1$ billion per year on labor market data collection and dissemination. 4 The LMIS of the United States, Canada, the United Kingdom, and Singapore, among several others, are touted as exemplary systems, although each has its own strengths and weaknesses. ${ }^{5}$ Consistent with other institutionalist trends, LMI is collected in more or less the same way the world around, in large part mirroring the most successful systems. The amount spent on LMI collection, the number and types of agencies involved, the frequency of data collection, and the quality of data vary; however, most countries collect LMI through periodic surveys of households, employers, and educators, and through the rollup of administrative system data (i.e., employment services data) to populate LMI data systems. ${ }^{5}$ Typically, these systems feed websites, periodic reports, print resources, and are channeled through social services staff, such as employment counselors, to constitute public access to LMI.

\section{Challenges to Traditional LMI}

Even the best LMIS suffer shortcomings, and less-developed countries encounter these problems to a greater degree. Traditional LMI is challenged in six key areas: timeliness, accuracy, integration, analysis, usage, and cost. ${ }^{6}$

- Timeliness: Survey results are too slow or are based on outdated classifications, calling into question the temporal validity of results when published.

- Accuracy: Poorly constructed surveys, nonrepresentative samples, and missing administrative data lead to questions of construct validity and selection bias.

- Analysis: Countries lack ability to turn labor market information into intelligence, leading to analytic bias and inaccurate result reporting.

- Integration: Data collected for multiple sources are not integrated into one system, leading to reporting bias.

- Usage: Usage challenged by access barriers and relevance/ demand issues are caused partly by funding bias.

- Cost: LMI systems are expensive, even cost prohibitive in low-resource regions, leading to government monopoly. 
Timeliness can severely affect the usefulness of LMIS, which suffers significant time lags from data collection to publication. For example, a February 2012 household survey conducted by the Government of Indonesia was not published until January 2014, a 2-year time lag in a fast-moving economy. In countries like the United States, monthly survey publication cuts back some of the time concerns, but does not eliminate them, because the surveys themselves are based on occupational classifications and other parameters that change much less frequently, meaning that careers such as web developer or social media specialist might not appear in official LMI data until years after they have become commonplace and in demand. To the extent that high-stakes decisions are made on LMI, the time relevancy of data will always be a concern. Data "velocity" is a primary attraction of big data, and most LMIS can benefit from faster data speed.

Accuracy of LMI is another concern, especially given the stakes of some of the decisions made based on LMI. In many LMIS, accuracy is challenged by typical selection bias and construct validity culprits of survey and sampling constraints (e.g., small, nonrepresentative samples or poorly constructed questionnaires) and administrative record limitations (skewed or missing data). In Sub-Saharan Africa, for example, 23 countries collect LMI from the administrative records of public employment agencies, but only 7 of these countries reach a threshold of $50 \%$ of job seekers using such services. ${ }^{7}$ In other places, challenges to basic survey methodology, fundamentals of good data collection practices, and unreliable processing are serious threats to the accuracy of the LMI collected. ${ }^{8}$

Analysis of labor market data transforms it from information to intelligence-analysis, interpretation, conclusions, and policy recommendations. To do this, many governments employ statisticians and labor market analysts, civil society groups produce research reports and data briefs, and privatesector consulting firms offer analytic services. However, in many countries these services are severely lacking, leading to analytic bias and rendering even the best collection systems inert. Recognizing this problem across multiple countries and projects, the ILO developed the Key Indicators of the Labour Market (KILM) database to help countries identify the core data they need to collect and why. The ILO also provides online software and tools to assist in analyzing data and creating labor market intelligence. A review of several current and recent past ILO and World Bank LMI support programs shows that training for labor market analysts is a core tenet of these reform programs, indicating the level of concern about analytic capacity gaps.
Integration of LMI collected by disparate ministries and agencies, not to mention nonpublic sources, challenges most systems-with "system" perhaps a misnomer given the scope of the integration challenge. As explained by Crouch, ${ }^{9}$ various government systems collect and contain complementary data (i.e., cost data and performance data) that paint a fuller picture and reduce reporting bias when fully integrated, but this integration is a challenge for stove-piped bureaucracies. Martin ${ }^{10}$ conducted a six-country study (Colombia, Costa Rica, Nicaragua, Ghana, Senegal, and Tunisia) of LMIS, and found that data integration is one of the greatest challenges to effective LMI in these countries, particularly troubling for his focus on the integration of migration data into an LMIS. The result of poor integration can go beyond problems of analytic depth, and can lead to missing signals and policy misalignment.

Usage is a combination of access, relevance, and "uptake" issues. Even when LMI is well collected, integrated, and analyzed, the best systems in the world are challenged by usage issues. In many countries, the internet is the preferred dissemination route; government-supported websites, such as those in the US (http://www.bls.gov/data/; http://www.mynextmove.org), are commonly used. Web-based dissemination is also supported by paper publications and in-person information dissemination through government offices and employment agencies in many countries. The quality of these services varies considerably, assuming those in need can even access them. To combat this, some countries rely on the media to carry the message. Simple searches in the United States for topics like "Hot Jobs 2016" returns results from major media outlets such as $\mathrm{CNN}$ and U.S. News and World Report, indicating active media coverage of LMI, a sign of user demand for such content. Media coverage is therefore a promising option for dissemination-challenged countries. Albania, for example, has a program to train the media on effectively covering LMI and creating attractive stories about it for users.

Yet access matters only in cases where the information is relevant and in demand. Publicly provided labor market data can suffer from funding bias, because these data are typically funded by and produced for policy makers or government users, not for a more diverse end user-individuals, education and training providers, employers, and community groups.

Finally, cost is a significant challenge to traditional LMI. The United States spends almost $\$ 1$ billion per year to run its LMIS, not counting significant state and local level investments-an amount that top US labor market economists have called insufficient. ${ }^{4}$ In Canada, the Conservative government came under fire from opposition parties for cutting Statistics Canada's budget and reducing LMI spending. In response, the Harper government announced a new $\$ 14$ million per year LMI 
investment, to some fanfare. Other countries spend far less on LMIS, but still devote nontrivial portions of limited budgets to it; and, given other pressing priorities, they may not be able to build bigger, better, more costly traditional LMIS. Nongovernmental actors can collect LMI through privately funded surveys and market research, but this work can be costly and complicated; therefore, such entities typically rely on public goods provided by the state and accept the limitations of these services.

\section{New Approaches to LMI}

The past 5 years have seen a rapid rise in new approaches to LMI that move beyond surveys as the primary data source, relying instead on novel data techniques such as online job posting analysis (JPA), social media analysis, crowdsourcing, and other big data-related sources. These approaches are called "real-time" LMI by some, 2,11 mostly due to the speed at which these data can be produced and analyzed, although the potential power of these approaches goes well beyond their impressive temporal achievements.

The most common form of real-time LMI is JPA, conducted by leading firms such as Burning Glass and Wanted Analytics. ${ }^{12}$ JPA entails "scraping" LMI from publicly available job postings on company websites, jobs boards, and newspaper classifieds, among other media. JPA firms employ natural languageprocessing techniques and advanced algorithms to analyze millions of job ads from thousands of sites each day, producing voluminous data on who's hiring, when, where, for what, and with what education and skill requirements. In some cases, JPA can also produce wage data. Its advantage is that it is real time (daily) and can represent actual job data, not projected hiring. Current users of JPA data include top colleges and universities, think tanks like the Brookings Institute, the US Federal Reserve Bank, the Governments of Singapore and Canada, and half of US states, among others.

Other forms of real-time LMI include mobile phone textmessage surveys, social media analysis, and some forms of crowdsourcing. For example, a company called GeoPoll uses relationships with mobile service providers across dozens of countries to survey mobile subscribers on a range of issues, including education and employment; surveys are sent out via text message and returned in a matter of days, costing as little as $\$ 4$ per response. ${ }^{\dagger}$ GeoPoll has deployed these surveys in challenging places like West Africa during the Ebola epidemic and the Democratic Republic of the Congo during its protracted civil war. A less tested data source comes from

$\dagger$ While the cost per respondent is low compared with traditional data collection techniques, the cost per bit of information is relatively high given the limited number of questions that can be asked via basic mobile survey. social media. In 2014, LinkedIn ran a competition inviting proposals for how its data could be useful to the economy. It received 250 submissions and selected 11 , including 8 that attempt to use LinkedIn data for LMI analysis. 13 This effort is part of LinkedIn's plans to economically graph the entire global economy (every employer, job, worker, and educational institution), and thus produce real-time data on the economy for a variety of users. This ongoing project is complemented by the efforts of Facebook, Google, and other media companies (e.g., see Facebook's search functionality: http://search.fb.com/).

Finally, groups like Glassdoor and CareerBuilder-which invite and use crowdsourced data on education and employment, including wage data, employer reviews, and labor supply data (resume banks) - have recently entered the business of analyzing these data for research and market intelligence services. Glassdoor opened a labor market research arm and CareerBuilder acquired the labor market research and consulting firm, Economic Modeling Specialists Intl. (EMSI). A new firm called Premise uses a variant of crowdsourcing, signing up thousands of "data contributors" who download the Premise app and collect bits of data-including labor marketrelated data-for micropayments, adding a layer of thirdperson quality control to such data.

The above-described techniques are all made available through advances in information communication technology and computational data science, fields that continue to rapidly advance. However, this fluidity makes comprehensive descriptions of real-time data analysis techniques difficult and quickly outdated; rapid change also challenges attempts at delineating the limitations of these approaches, as these, too, may change in the coming months and years. However, the limitations of these approaches are real, and include the following:

- Selection and Response Bias: Samples can be nonrepresentative due to coverage issues, self-selection, and self-reporting issues.

- Reliability and Validity: Data are not structured for LMI and can be inconsistent across sources and time.

- Incomplete Data: Variables are often omitted due to low coverage of wage and supply-side data.

- Cost and Access: Expensive, private systems are not available to a wide range of LMI users.

Selection and Response Bias: The collection and analysis of online data, or mobile data, may be biased toward those professions well represented online or users of mobile phones. This potentially skews data toward technology-intensive and 
professional services jobs at larger companies and away from other sectors and smaller employers-not to mention the informal economy, which is quite large in some developing countries. As mobile coverage is not 100 percent, surveys that rely on cell phones for data collection are not sampling the general population, but possibly only a privileged subset of it. Crowdsourcing and social media-based approaches similarly face sample selection and response issues given their selfselecting, self-reporting nature.

Reliability and Validity: Job postings are inherently unreliable, as one posting could be used to hire multiple people, or multiple postings to hire one person. Sometimes, ads are posted simply to test the market or collect resumes. There are also issues with duplicate postings (a job might be posted on a company's page as well as multiple job boards), although there are advanced methods for "deduplicating" these in analysis. Perhaps most problematic is that what is presented in an ad may have little to do with what is actually required or expected-a construct error. Last, geographic variables can be misleading; for example, a job posting might provide the address of corporate headquarters, but the job might actually be in another location.

Incomplete Data: A criticism of job posting analytics, the dominant source of real-time LMI, is that it is overly demand focused, and lacks novel ways to collect labor supply metrics and education and training data-although this is changing, with some firms developing resume analysis techniques and Glassdoor collecting wage data. These data are not structured in a theoretical, purposeful way, such that all angles and layers are covered; rather, they are extant data analyzed "as is" or as self-reported, often incomplete or inappropriate for the full analytic task at hand. On the mobile survey side, surveys can be better structured, but are limited to certain phrasing, character length, and constraints to follow-up questions, potentially leaving important data behind.

Cost and Access: Despite clear cost differences with traditional surveys, research and development and technology costs make access to privately held and licensed real-time LMI cost prohibitive for many, a situation that could change if governments develop their own approaches and make the data publicly available. At a Brookings Institution-hosted conference, James Vollman estimated that it would cost the US government $\$ 20$ million to $\$ 25$ million annually to develop and deploy JPA capabilities, a fraction of its current spending on traditional LMI.2 Currently, a "seat license" for one of the private providers costs about $\$ 10,000$ per year.
These limitations and considerations noted, the advance of real-time LMI approaches and services has led some observers to probe the implications for traditional LMI. Might real-time approaches replace traditional systems-or supplement them? How might the different sources be integrated in a way that achieves a greater sum of information not possible through one approach alone? Can big data save labor market information systems?

\section{Policy Implications}

To date, these questions have been tackled by US-based researchers studying the US economy, with little attention paid to the potential role of real-time LMI in LMIS reform in the developing world. In early 2013, a leading US labor market economist, Andrew Reamer, completed research on real-time LMI, including interviews with officials at the White House, the DoL, Congressional committees, the American Manufacturing Association, and the American Association of Community Colleges. The research sought to understand how much these organizations knew about real-time LMI, and what uses and value they saw in it for their agencies or organizations. Reamer found that real-time LMI has potential value in labor market research, preparing occupational profiles, monitoring and evaluation, and constitution services, among several others. He found that, although officials had some knowledge of and interest in real-time LMI, they cited equal or greater concern, skepticism, and barriers to its use (many covered in the previous section), including validity issues, cost constraints, and system integration limitations. Reamer ${ }^{14}$ concluded that as long as real-time LMI improves and becomes more accessible, its value will eventually win out and serve important, specific roles for these types of organizations.

Taking a wider lens, EMSI6 examined the general attributes of both traditional and real-time LMI (with a singular focus on job posting analytics), concluding that the strengths of each mitigate some of the weaknesses of the other, and calling for an integrated approach to using them together for greater impact. In a similar vein, a conference convened by the Brookings Institution outlined potential real-time LMI uses and concluded that "real-time LMI is a key lubricant to help remove friction from labor market transactions," calling on the US government to invest in it as a public good. ${ }^{2}$ Together, these reports can be seen as cautiously optimistic for use of real-time LMI in the United States, and as a general call for integrated approaches. In particular, these analyses are interpreted to lean in favor of using real-time LMI for "special purposes" by certain end users, but not as a harbinger of a day when these data would be relied on for general economic planning and high-stakes policy and budget decisions. 


\section{Implications for International Development}

To extend this line of inquiry and analysis to the developing world, I informally interviewed officials from four different multilateral organizations (World Bank, the ILO, the IDB, and the ADB) and one bilateral donor (USAID), seeking to understand what these officials knew about real-time LMI and gain their perspectives on its place in LMIS reform abroad.

In general, I found that the officials with whom I spoke were not immediately knowledgeable about real-time LMI. In all but two cases, some explanation was needed to familiarize respondents with the concept and approaches of real-time LMI. From that point, in each and every case, the officials interviewed expressed qualified interest in and optimism for such LMI innovations.

For example, David Kaplan, Senior Labor Market Specialist, IDB (currently based in Mexico), said, "I am not familiar with the concept, but I imagine it means taking advantage of all of the available information from any source (social networks, Google analytics, etc.) to find out as much as possible about the labor market. In principle the idea sounds very interesting to me." Maria Laura Sanchez Puerta, Senior Economist in the Jobs Group of the World Bank, echoed this statement, calling real-time LMI "interesting and important, with a lot of potential," after hearing a description of it. Dr. Sanchez Puerta's colleague, Michael Weber, was more immediately familiar with these concepts, and similarly expressed the World Bank's keen interest in them, giving some examples of the World Bank's past investments in these approaches.

Norman LaRoque, Principal Education Specialist at the ADB, was unfamiliar with the specific details of real-time LMI; but, when it was explained to him, he identified uses for it, hypothesizing that it could help with coordination problems among ministries, and triangulating data coming from other, more traditional LMIS sources. Souleima El Achkar, a consultant for the ILO, had been involved in national-level projects (such as in Vietnam) that used real-time LMI, but qualified, "I am familiar with real time LMI in that I am aware of it, and have seen it being collected/used, but have not directly used it myself." Jerry Wolgin, an economist at USAID, reported that his agency has used some mobile phone survey techniques to monitor labor market changes in real time, such as in West Africa after the Ebola outbreak. Dr. Wolgin saw potential for such approaches in monitoring key labor variables within a project or in the context of a timebound emergency, but questioned the veracity of such real-time data and their ability to inform advanced economic models, predictive analysis, and policy decisions. He also cautioned that the informality of the African labor market, and even the terminology used to describe work and employment, might complicate the adoption of advanced real-time approaches there.

The concerns voiced by USAID were echoed and added to by others. World Bank and ILO officials expressed concerns about sample biases, given the lack of internet penetration and use of the internet for job searches in many developing countries, especially in the informal economy. The World Bank also highlighted the traditional LMI concern about analytic capacity, citing previous attempts at using real-time LMI "grinding to a halt" as they ran into more pedestrian constraints of low-capacity data analysts and systems inadequate for integrating and analyzing various data sources. David Kaplan of the IDB questioned whether it might be better to focus attention on improving existing government administrative data to better support traditional LMI surveys.

Perhaps most clear was the common thread among respondents that real-time LMI might augment traditional LMI, or provide an interesting source of data for niche or ad hoc purposes. The notion that real-time LMI techniques of scraping job ads for data or looking to LinkedIn for skills trends would somehow be a routine part of LMI for economic planning or policy formation seemed a bridge too far. Souleima El Achkar, the ILO consultant, summed up this sentiment as follows:

In my opinion, this type of information has its place within developing country LMI systems, but priority should be given to high quality and timely collection and dissemination of traditional LMI. For policy and planning purposes (mid-term to long-term), real time LMI cannot substitute the invaluable information provided by the more traditional LMI. Of course, it can complement it. (E-mail correspondence with author)

A recent scandal in Canada related to use of real-time LMI for government decision making illustrates these concerns. For some time, Canada has been using job posting analytics and data from social media-related sites for LMI, such as the large classifieds site, Kijiji. In 2014, the Ministry of Finance in Canada used these data to highlight a gap in skill supply for certain sectors and industries, and thereby justified loosening immigration controls to create an influx of workers. Critics claimed that more traditional surveys from Statistics Canada showed a more even supply-demand match and that the government had incorrectly altered immigration policy based on shaky data. One member of Parliament quipped, "Kijiji's a great place to sell a bike, but this is no way to run an economy." 15 


\section{Conclusions}

The importance of LMI to efficient and equitable functioning of economies, and the challenges to traditional LMI remain. Real-time LMI is not a panacea, nor should it be seen as a replacement for troubled traditional approaches. Its use in the developing world must consider the economic and social factors that will challenge data collection and analysis in those regions. Yet, the ability of real-time LMI to overcome or improve the significant challenges of cost, time, and coverage makes it worth continued attention, research, and careful application.

Most promising, perhaps, is using real-time LMI for "special purposes" by specific clients that need different data or quicker data than that provided by the government, and are willing to accept real-time LMI's limitations to gain something novel and useful in return. Case examples of real-time LMI for special purposes are explained below.

- USAID worked with GeoPoll to conduct mobile phone text-messaging surveys during the Ebola outbreak in West Africa to track changes in labor force dynamics. USAID could not rely on slow government data, and was limited in its ability to conduct its own face-to-face surveys, given time and mobility constraints. Limitations of this survey method related to sample bias, nonresponse bias, and construct validity were palatable, given the reality of other constraints.

- Similarly, RTI International has piloted pared-down versions of traditional labor market surveys (labor demand, labor supply, and school-to-work transition) via mobile survey in Kenya. The customized surveys are providing localized data for stakeholder consultations in the design and startup phase of a youth workforce development project there. These data represent one source among others, including government data, qualitative focus group data, and data from existing projects in these areas. Steps were taking to increase mobile phone response rates and construct quality samples to decrease response and selection bias. The intended use, combination with other data, bias mitigation steps, and lack of usable, gold-standard data made this approach appropriate for the situation.

- In South Africa, RTI is trialing the use of LinkedIn to increase the labor market knowledge of marginalized job seekers. Working with youths in short-term training programs, treatment groups are being introduced to LinkedIn, given tips on its use, and provided computer lab time for exploring the site, versus control groups that are not given these tools. RTI will test for impact on differences in labor market knowledge, among other outcomes. The training provider is interested in this model-despite some obvious nonrepresentativeness and unstructured data issues - given the model's ease of use and LinkedIn's specific coverage of companies and job opportunities of interest to their students.

Extending these techniques to the developing world will allow LMI-dependent actors to use a variety of sources at a variety of time intervals to meet their needs, without foreshadowing the end of government systems and public provision of LMI.

\section{References}

1. Thuy P, Hansen E, Price D. The public employment service in a changing labour market. Geneva (Switzerland): International Labour Organization; 2001. 280 p.

2. Brookings Institute. [Internet]. Real time LMI. Washington DC: The Institute; 2016 [updated 2010 Sept 27]. Available from: http://www.brookings.edu/ /media/research/ files/speeches/2010/9/27\%20labor\%20statistics\%20 reamer/0927_labor_statistics_vollman.pdf

3. International Labour Organization. Labour market information and trends. Geneva (Switzerland): International Labour Organization; 2015. p. 1-2.

4. Reamer A. Putting America to work: the essential role of federal labor market statistics. Washington (DC): Brookings Institution; 2010. 70 p. Available from: http:// www.brookings.edu/research/speeches/2010/09/27-laborstatistics-reamer.

5. Mongozho N. Current practices in labor market information systems development for human resources development planning in developed, developing and transition economies. Geneva (Switzerland): International Labour Organization; 2003. 78 p.

6. EMSI. Contextualizing real time and traditional labor market data: the key perspective that hiring data provides and practical applications for using job postings and LMI in tandem. Spokane (WA): EMSI; 2015. 25 p.

7. African Development Bank, OECD Development Centre, UNDP, \& UNECA. African Economic Outlook 2012: Labour market information and matching-a problem for disadvantaged youth. Paris (France): OECD Development Centre; c2012 [updated 2015 May 28]. Available from: http://www.africaneconomicoutlook.org/.

8. Robison E. Statistical consulting with developing countries on labor force surveys [Internet]. Washington (DC): Bureau of Labor Statistics; 2010 [cited 2010 Dec 28]. Available from: http://www.bls.gov/osmr/pdf/st100160.pdf. 
9. Crouch LA. A relevant data revolution for development (RTI Press Publication No. PB 0007 1506). Research Triangle Park (NC): RTI Press; 2015. 8 p.

10. Martin I. Labour market information systems and labour migration information in six developing countries: the challenge of integration. Brussels (Belgium): International Organization for Migration; 2011. 89 p.

11. Milfort M, Kelley J. Innovations in labor market information and their application. Boston (MA): Jobs for the Future; 2012. 10 p.

12. Dorrer J, Milfort M. Vendor product review: a consumer's guide to real time labor market information. Boston (MA): Jobs for the Future; 2012. 15 p.

13. Perisic I. Announcing the winners of the LinkedIn Economic Graph Challenge. 2015 May 11. In: LinkedIn Official Blog [Internet]. San Francisco (CA): LinkedIn. com. Available from: http://blog.linkedin.com/2015/05/11/ announcing-winners-of-the-linkedin-economic-graphchallenge/.

14. Reamer A. Using real-time labor market information on a nationwide scale: exploring the research tool's potential value to federal agencies and national trade associations. Boston (MA): Jobs for the Future; 2013. 20 p.

15. Curry B, Grant T. Tories defend use of Kijiji data in face of opposition ridicule [Internet]. The Globe and Mail [updated 2014 Mar 26]. Available from: http://www. theglobeandmail.com/news/politics/tories-defend-use-ofkijiji-data-in-face-of-opposition-ridicule/article17690737/.

\begin{abstract}
About the Authors
Eric Johnson, PhD, is a senior research economist in the Workforce and Economic Opportunity Division at RTI International. He currently codirects RTI's Center for Global Youth Employment, with a focus on youth employment research and development. Dr. Johnson previously worked for the US Agency for International Development (USAID), where he served in Ghana and Vietnam, and was the agency's lead for Higher Education and Workforce Development while acting as deputy director of USAID's Office of Education. Dr. Johnson received his PhD in education and political science from Columbia University.
\end{abstract}

\section{Acknowledgments}

I am grateful to RTI International for an internal grant that allowed me to write this brief. In the process, I conducted interviews with the following officials and am grateful to each of them for their time and willingness to explore this topic: Alexandria Valerio, Maria Laura Sanchez Puerta, and Michael Weber of the World Bank; David Kaplan of the IDB; Norman LaRoque of the ADB, Jerry Wolgin of USAID; Ekkehard Ernst of the ILO; and Souleima El Achkar, an economist/ labor market information specialist working as a consultant for the ILO and the World Bank. Serena Williams of RTI International assisted in background research for this brief.

RTI Press Research Briefs and Policy Briefs are scholarly essays on policy, methods, or other topics relevant to RTI areas of research or technical focus.

RTI International, 3040 East Cornwallis Road, PO Box 12194 Research Triangle Park, NC 27709-2194 USA

+1.919.541.6000ｒtipress@rti.orgｗww.rti.org

C2016 RTI International. All rights reserved. Credit must be provided to the author and source of the publication when the content is quoted. No part of this publication may be reproduced in any form by any electronic or mechanical means without permission in writing from the publisher. RTI International is a registered trademark and a trade name of Research Triangle Institute.

RTI Press publication PB-0010-1608

www.rti.org/rtipress 